\title{
O afã de corrigir dos fonoaudiólogos: Uma posição pedagógica necessária?
}

\author{
The speech therapists correcting enthusiasm: A necessary pedagogical position? \\ El afán de corrección de los logopedas: ¿Una posición pedagógica necesaria?
}

Recebido: 22/07/2021 | Revisado: 29/07/2021 | Aceito: 01/08/2021 | Publicado: 06/08/2021

\author{
Ana Paula Marcelino Ramos \\ ORCID: https://orcid.org/0000-0003-4397-3024 \\ Universidade Estadual de Campinas, Brasil \\ Prefeitura Municipal de Americana, Brasil \\ E-mail: marcelinoana@hotmail.com \\ Irani Rodrigues Maldonade \\ ORCID: https://orcid.org/0000-0002-5607-7344 \\ Universidade Estadual de Campinas, Brasil \\ E-mail: irani@fcm.unicamp.br
}

\begin{abstract}
Resumo
Este artigo buscou refletir sobre as práticas adotadas por uma fonoaudióloga no atendimento de duas crianças com dificuldades escolares. Para tanto, as concepções de língua(gem) e sujeito foram tomadas criticamente a partir da teorização interacionista, de forma a estabelecer um contraste entre a Fonoaudiologia Tradicional e a Clínica de Linguagem. As sessões fonoaudiológicas foram filmadas, transcritas e analisadas de acordo com os pressupostos da Clínica de Linguagem, adotando-se, portanto, uma metodologia qualitativa e descritiva. Os dados selecionados para investigação se referiam aos momentos em que a terapeuta corrigia erros na fala, leitura e escrita das crianças. Durante os atendimentos, a posição pedagógica da terapeuta se destacou, de modo que a criança era colocada na posição de aprendiz e a fonoaudióloga na posição de quem ensina e corrige, evidenciando práticas ligadas à Fonoaudiologia Tradicional. A partir da escuta das transcrições, a terapeuta pode se distanciar da cena clínica, reinterpretar as manifestações linguísticas das crianças (não apenas como erros ou acertos) e, com isso, rever criticamente a sua prática. Escutar a transcrição das sessões promoveu uma mudança de posição da terapeuta em relação a sua própria fala e a das crianças. A adesão à metodologia proposta pela Clínica de Linguagem permitiu concluir que a posição pedagógica não é uma posição necessária para a prática fonoaudiológica.
\end{abstract}

Palavras-chave: Fonoaudiologia; Clínica de linguagem; Fala e escrita.

\begin{abstract}
This paper aimed to reflect on the practices adopted by a speech therapist in the care of two children with learning difficulties. For that, the conceptions of language and subject were taken critically from the interactionist theorization, in order to establish a contrast between Traditional Speech Therapy and the Language Clinic. The speech therapy sessions were filmed, transcribed and analyzed according to the premises of the Language Clinic, therefore adopting a qualitative and descriptive methodology. The data selected for investigation referred to the moments when the therapist corrected errors in the children's speech, reading and writing. During the speech therapy sessions, the pedagogical position of the therapist stood out, so that the child was placed in the position of learner and the speech therapist in the position of who teaches and corrects, showing practices related to Traditional Speech Therapy. After listening to the transcriptions, the therapist could distance herself from the clinical scene, reinterpret the linguistic manifestations of children (not only as errors or hits) and, therefore, critically review her practice. Listening to the transcription of the sessions promoted a change in the therapist's position in relation to her own speech and that of the children. The option for the methodology proposed by the Language Clinic allowed us to conclude that the pedagogical position is not a necessary position for speech therapy practice.
\end{abstract}

Keywords: Speech therapy; Language clinic; Speech and writing.

\section{Resumen}

Este artículo buscó reflexionar sobre las prácticas adoptadas por un logopeda en el cuidado de dos niños con dificultades escolares. Por tanto, las concepciones de lengua(je) y sujeto fueron tomadas críticamente de la teorización interaccionista, con el fin de establecer un contraste entre la Fonoaudiología Tradicional y la Clínica del Lenguaje. Las sesiones de logopedia fueron filmadas, transcritas y analizadas de acuerdo con los supuestos de la Clínica del Lenguaje, adoptando por tanto una metodología cualitativa y descriptiva. Los datos seleccionados para la investigación se referían a los momentos en que el terapeuta corrigió errores en el habla, lectura y escritura de los niños. Durante las sesiones se destacó la posición pedagógica del terapeuta, por lo que se colocó al niño en la posición de aprendiz y al logopeda en la posición de quien enseña y corrige, mostrando prácticas vinculadas a la Fonoaudiología Tradicional. Al escuchar las transcripciones, el terapeuta puede distanciarse del escenario clínico, 
reinterpretar las manifestaciones lingüísticas de los niños (no solo como errores o aciertos) y, por lo tanto, puede revisar críticamente su práctica. Escuchar las transcripciones de las sesiones propició un cambio en la posición de la terapeuta en relación con su propio discurso y el de los niños. La adherencia a la metodología propuesta por la Clínica del Lenguaje permitió concluir que el puesto pedagógico no es un puesto necesario para la práctica logopédica.

Palabras clave: Logopedia; Clínica de lenguaje; Habla y escritura.

\section{Introdução}

Este artigo buscou refletir sobre a posição da terapeuta frente aos erros de fala, leitura e escrita de crianças submetidas ao atendimento fonoaudiológico. Nele, serão priorizados os dados em que a fonoaudióloga corrige as manifestações linguísticas de duas crianças. Para tanto, as concepções de língua(gem) e sujeito serão tomadas criticamente a partir da teorização interacionista desenvolvida por De Lemos (2002, 2006, 2015) e colaboradoras (Lier-De-Vitto, 2004, 2006, 2008; Maldonade, 2011, 2016, 2018), de forma a estabelecer um contraste entre a Fonoaudiologia Tradicional e a Clínica de linguagem.

A história mostra a vinculação (ou aproximação) da Fonoaudiologia com a Educação e a Saúde (Berberian, 2007; Didier, 2001). Inicialmente, por volta de 1920, não havia cursos que formassem fonoaudiólogos no Brasil. Então, médicos, enfermeiros, educadores e, posteriormente, os psicólogos se encarregavam de englobar as patologias da linguagem entre suas preocupações. De certa forma, isso pode explicar o uso de termos empregados pelo fonoaudiólogo até hoje (Meira, 1996), tais como: "diagnóstico", "patologia", "prognóstico" e "evolução", que são considerados empréstimo da Medicina, bem como a dicotomia "certo/errado", tomado como empréstimo da Educação, assim como as teorias de aprendizagem e desenvolvimento, oriundas da Psicologia. Para além dos termos emprestados de outras áreas, pode se ver, frequentemente, terapeutas assumindo posições pedagógicas, reduzindo as ações fonoaudiológicas à educação (aprendizagem), apagando o fazer da clínica e na clínica. Desta forma, torna-se importante neste artigo refletir, mais atentamente, sobre a posição que o fonoaudiólogo assume no setting terapêutico, quando se espera que ele possa, de certa maneira, promover mudanças significativas na relação da criança com a língua(gem).

O termo Fonoaudiologia Tradicional é aqui definido como uma clínica que se constituiu (e se constitui até os dias de hoje) iluminada pelo discurso médico-pedagógico centrada nos valores praticados nos primórdios da construção do campo fonoaudiológico.

Amparada pelo discurso médico, a Fonoaudiologia Tradicional vem se dedicando a desenvolver protocolos de avaliação e técnicas terapêuticas, tentando cumprir exigências do paradigma quantitativo, que também é o vigente nas ciências da saúde (Rubino, 1994; Arantes, 2019). No caso da avaliação de linguagem, o diagnóstico acaba sendo alinhado às descrições das doenças incrementado por uma aproximação da Linguística (a das formas) e/ou da Psicologia (principalmente, a do desenvolvimento). Sendo assim, o lugar da linguagem fica limitado as questões relativas ao funcionamento linguístico e do sujeito são excluídas do escopo da avaliação e do processo terapêutico em linguagem.

Na perspectiva da Fonoaudiologia Tradicional, a língua(gem) é concebida como se fosse um objeto, cuja aquisição pode ser vista como uma série ordenada de emergência de estruturas na fala e/ou escrita, extraídas da descrição linguística e tomadas numa suposta ordem crescente de complexidade (das mais simples para as mais complexas). Nesta lógica, o processo de aquisição é encarado como homogêneo para todos os sujeitos, além de poder ser também definido como um processo de aprendizagem (De Lemos, 2006). Tal visão é contrária a da proposta interacionista desenvolvida por De Lemos e colaboradoras, que propõe o processo de aquisição como um processo de mudanças, sendo estas linguísticas e subjetivas. Desta forma, a língua(gem) é concebida como um “objeto" de contornos não nítidos, heterogênea, além de estar em constante movimento. 
A noção de desenvolvimento adotada pela Fonoaudiologia Tradicional é também muito frequente em vários estudos relacionados à aquisição de leitura e escrita. Schirmer et al. (2004) acreditam que a leitura aconteceria em duas etapas. Na primeira etapa ocorreria a análise visual, através do processamento viso-perceptivo do estímulo gráfico; e na segunda etapa, se daria o processamento linguístico da leitura, onde, através da via não lexical, seria feita a conversão grafema-fonema e, pela via lexical, seria feita a leitura global da palavra com acesso ao significado.

Nesta mesma direção, Teixeira (2005) destaca que a aprendizagem do ato de ler e escrever, no campo da história da fonoaudiologia, determinou-se pelo preenchimento de pré-requisitos básicos, dispostos numa sequência, que passaria pela habilidade do sujeito de identificar e discriminar letras e sons, associando letras aos sons correspondentes. Para tanto, considerava ser necessário que o sujeito tivesse suas competências de memória íntegra, raciocínio, coordenação visual e motora para completar esse processo. A autora mostra que a prática de leitura e escrita se centra, na Fonoaudiologia Tradicional, em atividades realizadas por meio de ditados, cópias e leituras por meio de palavras isoladas e frases soltas sem ligação com a realidade da criança.

Nesta perspectiva, as manifestações de leitura e escrita não convencionais são apontadas como sinais de dificuldades intrínsecas aos sujeitos, indicando o comprometimento das habilidades linguístico-cognitivas, como por exemplo, as dificuldades de memória de curta duração, dificuldades em recuperar representações fonéticas/fonológicas, dificuldades em identificar palavras faladas na presença de ruídos, entre outras (Capellini, 2004; Zorzi, 2004). Por este raciocínio, as dificuldades e alterações de linguagem seriam atribuídas ao próprio sujeito. Portanto, seriam de caráter endógeno. Além disso, é possível observar a tendência da Fonoaudiologia Tradicional em acreditar que o processo de leitura e escrita aconteceria de forma linear, gradual e hierárquica (Zorzi, 2004).

Logo, os planejamentos terapêuticos na Fonoaudiologia Tradicional costumam se valer de programas terapêuticos pré-determinados ou atividades, que consideram a linguagem como um conjunto de estruturas (formas linguísticas) passíveis de hierarquização, dividindo-as em categorias ou habilidades (tais, como: identificação e discriminação letras e sons, associação de letras aos sons correspondentes, dentre outros). Nesses programas, os erros e/ou acertos do indivíduo são quantificados para que ele possa passar para um próximo nível, tido como mais complexo.

Sendo assim, a terapêutica consiste no treinamento das habilidades com a língua tomada como objeto aliando-se à noção de sujeito, encarado como o aprendiz. Em outras palavras, a língua é vista como objeto de conhecimento e seu domínio supõe a superação de etapas (estágios) de graus de sua complexidade. Assim, a criança é tomada como alguém que se posiciona em relação à língua, dominando-a paulatinamente (Saleh, 2008), enquanto que a posição da terapeuta é a de quem detém o saber e o controle sobre a língua, na cena terapêutica. Ou seja, a posição reservada à terapeuta é a de quem ensina a língua à criança (paciente).

No entanto, as práticas que regem a Clínica Tradicional não respondem à maioria das inquietações que emanam da clínica. Uma delas diz respeito ao papel do fonoaudiólogo, que tem que lidar com a heterogeneidade e imprevisibilidade da fala, leitura e escrita, já que uma mesma criança pode apresentar tanto expressões corretas como incorretas numa mesma sessão de atendimento, às vezes até no mesmo enunciado. Outra dificuldade é que o processo de aquisição da linguagem não é o mesmo para todas as crianças. Além disso, às vezes o terapeuta se depara com produções textuais corretas do ponto de vista da ortografia, mas inapropriadas do ponto de vista da construção dos sentidos.

Deparando-se com os limites que as concepções de língua e sujeito impõem à atuação do fonoaudiólogo na Fonoaudiologia Tradicional, é que se buscou na Clínica de Linguagem, uma alternativa para iluminar as questões que emanam da clínica. Entre elas, a reflexão sobre a posição da terapeuta, tema deste artigo.

A teorização desenvolvida por De Lemos $(1982$, 2002) e colaboradoras caracteriza-se frente aos outros modelos teóricos da área de Aquisição da Linguagem por tomar a interação com o outro, como a condição necessária para o processo de 
aquisição da linguagem pela criança. Apesar das reformulações que sofreu ao longo dos tempos, este pressuposto nunca foi alterado.

O interacionismo recusa-se a analisar a fala da criança pelas categorias oferecidas pela descrição linguística ou mesmo a tomar os enunciados das crianças como evidência de conhecimento da língua. Tomando outra direção, desenvolveuse para explicar como as propriedades formais da língua(gem) poderiam ser derivadas de processos de interação linguísticodiscursivos. Desta forma, De Lemos (1992) lançou a proposta dos processos metafóricos e metonímicos como mecanismos que poderiam explicar as mudanças linguísticas ocorridas ao longo do processo de aquisição da linguagem pela criança. E, mais tarde, em 2002, De Lemos integrou os efeitos desses processos à articulação da posição do sujeito no processo de aquisição da linguagem, lançando a proposta das três posições da criança no processo de aquisição da linguagem (De Lemos, 2002). A autora assinala que as mudanças que ocorrem durante o processo de aquisição da linguagem são mudanças relativas à fala do outro, à língua e à fala da própria criança. Com isso, ela afirma que essas mudanças são linguísticas e também subjetivas. Conclui-se então, que descrever a fala da criança não é tarefa simples, pois significa descrever algo em constituição e, ao mesmo tempo, em mudança linguística. Este desafio também é (ou deve ser) enfrentado pelo fonoaudiólogo nas terapias.

Além disso, o processo de aquisição da linguagem é visto como processo de subjetivação, ou seja, ele é único para cada criança e a língua é concebida segundo Maldonade (2003, p. 25) como "um sistema heterogêneo, o que equivale a dizer que a diversidade dela é constitutiva, e é dinâmica, portanto, está em constante movimento".

Desta forma, o interacionismo se distancia de outras abordagens (especialmente as vinculadas a Fonoaudiologia Tradicional) pela concepção de língua(gem) e de sujeito adotadas, afastando-se das propostas de aprendizagem e cognitivistas (De Lemos, 2000, 2002; Maldonade, 2010; Schavarem et al., 2020).

$\mathrm{Na}$ teorização interacionista, a fala do outro é tomada como instância discursiva. É neste sentido que se torna importante refletir sobre a posição assumida pela(o) fonoaudióloga(o) em relação à fala da criança, no contexto terapêutico. Isso é possível na medida em que os conceitos de língua(gem) e sujeito são tomados criticamente. Ressalta-se que neste artigo, o outro não é qualquer interlocutor, mas é o outro-terapeuta, que lida diretamente com o sofrimento que emerge das alterações de linguagem. Por isso, faz-se necessário uma aproximação com a Clínica de Linguagem, que vem sendo proposta por LierDe-Vitto desde a década de 90, tendo se originado com o desenvolvimento do Projeto Aquisição, Patologia e Clínica de Linguagem no LAEL/PUCSP (Lier-de-Vitto \& Andrades, 2008, p 62). Para Lier-De-Vitto,

(...) outro deve ser pensado em sua especificidade de outro-terapeuta, quanto mudança, já que ela fica condicionada a um ato clínico (uma interpretação) que, esperasse, possa incidir sobre o sintoma. No âmbito dessa interação particular, refletir sobre a problemática da interpretação envolve considerar a dissimetria sujeito-outro, instituída no setting clínico, e a necessidade de especificar a posição do terapeuta. (Lier- De-Vitto, 2005, p.145)

Para além da posição do outro-terapeuta, a Clínica de Linguagem ao se voltar para as Patologias de Linguagem, reconhece as especificidades das produções consideradas sintomáticas da fala/escrita e tem caminhado junto com a teorização interacionista, uma vez que suspendem a noção de sujeito aprendiz e passam a enfrentar a fala da criança, sempre se aproximando da Linguística e da Psicanálise para tecer suas considerações (Lier-De-Vitto \& Andrade, 2008).

Dessa forma, o termo Clínica de Linguagem é utilizado em oposição à Fonoaudiologia Tradicional, para demarcar diferenças teóricas e clínicas de cada uma delas. Neste sentido, cabe ressaltar que as concepções de sintoma, erro e patologia que aparecem na Clínica de Linguagem guardam diferenças relevantes com as concepções adotadas pela vertente Tradicional da Fonoaudiologia.

$\mathrm{Na}$ Clínica Tradicional, ao se conceber a linguagem enquanto objeto de conhecimento, o erro e o sintoma ganham praticamente o mesmo status. Em outras palavras, quando a criança apresenta um erro que não condiz com o esperado para sua idade e escolaridade, ele ganha contorno de sintoma e, por conseguinte, vira sinal patológico. O que se observa é que a escrita, 
leitura e fala das crianças são descritas através das categorias da gramática (normativa), impossibilitando diferenciar o erro de sintoma. E para explicar o erro, a clínica tradicional, recorre a aspectos cognitivos, sociais e orgânicos, segundo Fongaro (2009). No interacionismo, o erro é tido como dado privilegiado de análise, através do qual se mostra mais de perto a relação da criança com a língua. Alguns erros são exemplares ao exibir como as relações vão se construindo de forma única na fala/escrita da criança em processo de aquisição da linguagem, o que possibilitou concluir que esse trajeto não é o mesmo para todas as crianças. Para o interacionismo, o erro marca o funcionamento da língua no sujeito, pois revela um distanciamento em relação à fala do outro e a sua própria fala, deixando em evidência a língua, enquanto funcionamento (Ferreira, 2011).

Ao se situar na Fonoaudiologia Tradicional, o terapeuta poderá tomar as unidades linguísticas da descrição gramatical sem críticas, contabilizar o erro na fala e/ou escrita, verificar se ele é esperado ou não para a idade e escolaridade da criança, de acordo com escalas de desenvolvimento. O tratamento que isso recebe na Clínica de Linguagem é outro. Será necessário suspender a informação dada pelos aparatos descritivos da língua e decidir como se lidará com ele. De modo geral, considerase que há sintoma quando existe uma fixação da criança numa mesma posição, o que de certa forma, pode ser visto como uma espécie de cristalização do erro. Com isso, o sujeito não consegue se deslocar para outra posição no processo de aquisição da linguagem. Logo, o sintoma é aquilo que provoca "efeito de patologia na escuta dos falantes (e, muitas vezes, na do próprio sujeito), ou seja, essa escuta afeta aquele que fala" (Lier-De-Vitto, 2006). Embora Lier-De-Vitto (2006) tenha se referido mais aos sintomas da fala, cabe lembrar que as manifestações sintomáticas relativas à leitura e escrita também são notadas (Lier-DeVitto \& Andrade, 2008).

Um ponto importante a ser considerado é que as crianças que são encaminhadas para avaliação fonoaudiológica, sofrem. E, nesse sofrimento, estão também incluídos os pais, que buscam explicações ou causas para as "dificuldades" que a crianças enfrentam no processo de aquisição de leitura e escrita - e os professores, que em uma sala com várias crianças em processo singular, se afligem com aqueles que apresentam "erros", aparentemente permanentes e fixos. Então, fica evidente que da "noção de sintoma participam tanto o ouvinte" (professor, pais, colegas de turma), "que não deixam passar uma diferença, quanto o falante" (escrevente, leitor) "que não pode passar a outra coisa" (Lier-De-Vitto, 2006, p. 185).

Logo, ao colocar uma criança com sintomas relacionados ao processo de aquisição da leitura e escrita em terapia fonoaudiológica, espera-se que a criança deixe sua posição fixa no sintoma e ganhe novos deslocamentos em seu processo de aquisição. No processo terapêutico também se trabalha para desconstruir os rótulos, que acabam por identificar as crianças negativamente na família e sociedade.

É preciso deixar claro que, ao preparar e realizar as terapias fonoaudiológicas, a terapeuta ainda estava guiada pelas concepções da Fonoaudiologia Tradicional, ou seja, ainda estava presa à ideia de desenvolvimento e a visão do erro como déficit ou falta de conhecimento. Dessa forma, ficou em evidência a posição pedagógica assumida pela fonoaudióloga nas terapias, o que motivou a reflexão sobre o tema no momento seguinte, na transcrição e análise dos dados, quando a terapeuta tinha se aproximado do interacionismo e da Clínica de Linguagem.

O compromisso da terapeuta deve ser com a fala, a escrita e leitura das crianças no processo terapêutico. Neste sentido, os enunciados podem ou devem constituir um enigma para o investigador. Para De Lemos (1992), o outro (terapeuta) é sede do funcionamento linguístico, o que lhe permite interpretar a fala, escrita das crianças, ainda que o efeito dessa interpretação seja imprevisível e se deixe ver apenas mais tarde, na relação da criança com a fala do outro (interlocutor adulto).

A interpretação do terapeuta, normalmente, é diferente da interpretação de quaisquer outros interlocutores, pois o terapeuta é guiado pela teoria de linguagem a qual se filia. O terapeuta da clínica de linguagem deve ter cuidado para que não seja colocada uma barreira à escuta para heterogeneidade da fala (Santos, 2017), leitura e escrita da criança. Normalmente, o terapeuta da Fonoaudiologia Tradicional, que se deixa guiar pelos aparatos descritivos da Linguística corre o risco de ter sua escuta barrada, uma vez que prioriza a língua enquanto "objeto", que supõe ser o mesmo e transparente para a criança. 
Em contrapartida, na teorização interacionista e na Clínica de Linguagem, o outro (terapeuta) torna-se decisivo na explicação das ocorrências da escrita/fala, já que seu enunciado pode ser determinante para a fala/leitura/escrita da criança, quando o efeito de interpretação é alcançado. Sendo assim, a posição do terapeuta no atendimento fonoaudiológico e fora dele (enquanto investigador) sempre é interrogante, uma vez que lida com o imprevisível da língua(gem). Tal imprevisibilidade coloca em xeque o saber do terapeuta sobre o que vai emergir da fala, leitura e escrita da criança para que assim possa se abrir a escuta e comprometer-se de fato com a singularidade do processo de aquisição de linguagem.

Para garantir o compromisso com a singularidade da fala, a recomendação de Arantes (2001) é: “ler depois de clinicar", o que pode facilitar o manejo clínico, uma vez que a transcrição das falas do paciente e da terapeuta pode auxiliar na apreensão dos efeitos que cada uma exerce na outra. Esta tem sido a metodologia usada pela Clínica de Linguagem.

Na passagem do "escutar na clínica" para o "ler depois do clinicar” segundo Arantes (2001) e Lier-De-Vitto (2004), o clínico se divide em duas posições: a primeira é a da "interpretação em cena", em que ele está sob o efeito das produções dos pacientes. Nela, o clínico não pode prever o que vai ser dito nem os efeitos que a fala do paciente produzirá nele. A segunda posição refere-se ao depois da cena clínica, em que o terapeuta se apresenta como o investigador. Ao se distanciar da cena clínica, realizando as transcrições, o terapeuta assume a posição de investigador e invoca a escuta, guiando-se pela teoria de linguagem assumida (implícita ou explicitamente). Arantes (2019) propõe que a fala do instante clínico permaneça viva na escuta do clínico no momento da transcrição. A autora refere, ainda, que a escuta do clínico é "clínica", se esta for teoricamente guiada. Dessa forma, as transcrições não podem anular os efeitos da fala viva, nem a leitura/interpretação clínica pode ser tomada como equivalente à intuição do falante nativo, já que a interpretação está sujeita a uma ilusão de fala.

Lier-De-Vitto e Emendabili afirmam que

uma escuta penetra a outra, que não são dissociadas, mas integradas. Vale chamar a atenção para o fato de que não há transcrição que não seja já uma interpretação, por mais que seja guiada pela atenção, por mais que seja regida pela ilusão de reprodução de fala. Ora, aquele que transcreve, transcreve com sua orelha de falante. Por aí, a transcrição traz um tanto da escuta da sessão. (Lier-De-Vitto \& Emendabili, 2015, p. 81)

Sendo assim, neste artigo, com o propósito de refletir sobre a posição do terapeuta durante as sessões de atendimento fonoaudiológico, a transcrição, na clínica de linguagem pode favorecer a leitura do diálogo, possibilitando uma interpretação da fala/leitura/escrita da criança, do terapeuta e do efeito recíproco que uma exerce(u) sobre a outra.

\section{Metodologia}

Este trabalho é um recorte e fruto da dissertação de mestrado "Reflexão sobre as posições de terapeuta frente às dificuldades de leitura e escrita na clínica fonoaudiológica" (Ramos, 2018). Ele se caracterizou como uma pesquisa qualitativa, que visou refletir sobre a posição assumida pela fonoaudióloga ${ }^{1}$ frente aos "erros" de leitura, fala e escrita das crianças participantes da pesquisa. A metodologia desta pesquisa se inspirou na adotada pela Clínica de Linguagem e interacionismo e consistiu da gravação (filmagem) de 12 sessões de atendimento fonoaudiológico, para posterior transcrição (larga) dos diálogos, de forma a incluir tanto as falas das crianças, quanto a do terapeuta, como unidade de análise. Os dados também foram analisados com base na teorização interacionista

\footnotetext{
${ }^{1}$ A fonoaudióloga (e também pesquisadora) é profissional concursada da Secretaria de Saúde da Prefeitura Municipal de Americana/SP desde 2011. Desde o início de sua trajetória profissional vem se dedicando ao atendimento de crianças com dificuldades na área de linguagem, explicando seu interesse pelo tema. Ela foi a terapeuta responsável pelo acompanhamento fonoaudiológico das crianças selecionadas para a pesquisa de mestrado. Para obter outras informações, sugere-se a leitura da Introdução da dissertação de mestrado "Reflexão sobre as posições de terapeuta frente às dificuldades de leitura e escrita na clínica fonoaudiológica", defendida em 2018.
} 
A coleta de dados da pesquisa foi autorizada pelo Comitê de Ética da Universidade Estadual de Campinas sob o número 56915016.1.0000.5404 e realizada na Clínica de Fonoaudiologia da Prefeitura de Americana/SP no segundo semestre de 2016, mais especificamente, foi iniciada em agosto de 2016 e finalizada em maio de 2017. As filmagens das sessões de atendimentos fonoaudiológicos foram feitas com uma câmera digital Samsung 16 mpx.

De acordo com os critérios de inclusão dos participantes na pesquisa, foram selecionadas 6 crianças de 8 a 11 anos, uma vez que é nessa faixa etária que há maior demanda para avaliação fonoaudiológica de crianças com queixas relacionadas às dificuldades de leitura e escrita. As crianças estavam todas regularmente matriculadas no ensino fundamental. Elas foram distribuídas em dois grupos, levando-se em consideração: a data mais antiga de avaliação fonoaudiológica na clínica e a idade delas. Como na Clínica de Fonoaudiologia de Prefeitura de Americana os atendimentos são sempre realizados em grupos, a coleta obedeceu esta mesma configuração.

A composição dos grupos de crianças foi feita levando-se em consideração a idade delas e a semelhança das queixas apresentadas. Desta forma, buscou-se favorecer a integração dos sujeitos no grupo e facilitar as escolhas das estratégias e materiais utilizados pela fonoaudióloga nas sessões de terapia.

Os atendimentos fonoaudiológicos foram quinzenais, com a duração de 60 minutos, sendo que os primeiros 45 minutos foram destinados ao atendimento das crianças e os últimos 15 minutos, reservados para conversa com os responsáveis por elas. Para este artigo, foram selecionados apenas os dados de duas crianças (M e I, ambas com 10 anos de idade), que davam visibilidade ao fenômeno estudado, ou seja, à posição pedagógica da fonoaudióloga, tema deste artigo. Os dados das outras crianças não foram aqui incluídos, pois eles se referem a outro tipo de fenômeno, relacionado aos momentos em que a fonoaudióloga "barra" os sentidos produzidos pelas crianças em seus textos (orais, escritos ou lidos), fazendo com que elas se calassem, ou seja, assinalando uma outra posição da fonoaudióloga frente às dificuldades de leitura e escrita² ${ }^{2}$

As sessões seguiram um planejamento terapêutico prévio, elaborado pela terapeuta, em que as atividades propostas foram didaticamente divididas e desenvolvidas em quatro etapas: 1) leitura compartilhada de um livro infantil (ora escolhido pela terapeuta, ora pelas crianças). As obras utilizadas durante os atendimentos fonoaudiológicos foram os livros de Sônia Junqueira: (a) O peixe pixote; (b) O barulho fantasma; de Mary França e Eliardo França: (c) Na roça; (d) Pote de Melado; de Regina Renó: (e) Doce água doce; de Sônia Barros: (f) Tatu-balão e de Fanny Joly: (g) Quem tem medo de Lobo?; 2) produção escrita das crianças referente ao livro; 3 ) leitura do texto das crianças, sendo que cada uma deveria ler o seu próprio texto e 4) leitura realizada pela terapeuta (em voz alta) dos textos feitos por cada criança. Cabe ressaltar que, depois da leitura compartilhada, foram feitas discussões sobre o livro lido. Os textos produzidos pelas crianças às vezes tinham desenhos feitos por elas.

O planejamento tornou-se uma espécie de script, que fornecia não só a direção para o atendimento, mas também uma certa sensação de segurança para a terapeuta, achando que, desta forma, poderia ter o controle da sessão.

Com base nessas etapas, serão apresentados três episódios, na próxima seção, que ilustram a posição pedagógica da fonoaudióloga.

\section{Resultados}

Os dados, a seguir, mostram a preocupação da terapeuta (que ainda se situava na Fonoaudiologia Tradicional) com a correção da fala, leitura e escrita das crianças em atendimento fonoaudiológico. Em alguns momentos, ela se voltava para exigir a ortografia correta na escrita das palavras e, em outros momentos, se voltava para a correção dos fonemas na fala das

\footnotetext{
${ }^{2}$ Para acessar os dados de outras crianças e obter mais detalhes sobre a posição assumida pela fonoaudióloga, pode-se consultar o capítulo 6 , "Apresentação e análise de dados", da dissertação de mestrado "Reflexão sobre as posições de terapeuta frente às dificuldades de leitura e escrita na clínica fonoaudiológica".
} 
crianças. Neste sentido, Araújo (2002) destaca que as estratégias adotadas na Fonoaudiologia Tradicional são amparadas pelo "imaginário da existência de um padrão de desenvolvimento a ser seguido como norte para o encaminhamento das "ações terapêuticas", delineando os contornos de uma "clínica pedagógica", ao acreditar que haveria uma linha única e uniforme de "desenvolvimento" da linguagem a ser perseguida" para todas as crianças. Nesta posição, a terapeuta trabalha com a ilusão de que a língua(gem) é também homogênea e transparente, bastando no seu papel oferecer o padrão correto de fala e escrita às crianças que necessitam de seu auxílio.

Assim, é possível conferir no episódio abaixo, as atitudes corretivas da terapeuta (T) no setting terapêutico:

\section{Episódio 1 - A escrita foi inspirada pelas figuras do livro Doce água doce ${ }^{3}$}

Situação: Crianças perguntavam para fonoaudióloga como deveriam escrever algumas palavras enquanto produziam seu texto. M: como escreve chega?

T: Vou te ajudar. Como é / $/$ ?

M: $\mathrm{x}$

T: Outra letra que o som parece?

M: Ah (escreveu chega corretamente)

I: Barragem é com x ou com z?

$\mathrm{T}$ : nem com $\mathrm{x}$ e nem com $\mathrm{z}$. $3 /$ (produz o fonema, alongando-o)

$\mathrm{I}: \mathrm{j}$

T: Com g.

No episódio 1, M perguntou à terapeuta como deveria escrever a palavra chega e, na sequência I perguntou sobre como deveria escrever a palavra barragem. As respostas da terapeuta mostraram a direção pedagógica da terapia, em que os fonemas $/ \mathrm{J} / \mathrm{e} / \mathrm{z} /$ foram produzidos com alongamentos por ela, para facilitar a seleção do grafema correspondente na escrita da criança. Como se isso fosse uma tarefa fácil e evidente para as crianças! Ao fazer esses prolongamentos, a opacidade da língua(gem) é apagada pela fonoaudióloga, pois a relação entre fonema-grafema nem sempre é direta e unívoca, muito menos transparente. Ao alongar o fonema, possivelmente foi salientado o que a criança deveria mudar em sua escrita.

Observa-se, ainda que a terapeuta se posicionou como alguém que detinha o saber e queria ensinar a língua às crianças, colocando-as na posição de aprendiz, forçando-as a trabalhar na relação grafema-fonema.

Nesse momento da sessão, ao lidar com o erro da forma destacada acima, a terapeuta aproximava-se dos pressupostos da Fonoaudiologia Tradicional, uma vez que manipulava a língua, como se fosse um objeto e procurava ensinar a criança, ao mesmo tempo, que buscava mediar a relação da criança com a língua. Em contrapartida, na Clínica de Linguagem o outro é concebido como instância da língua em funcionamento, de modo que ele é retirado da condição de sujeito epistêmico, mediador da relação da criança com o objeto (Araújo, 2002).

A posição assumida pela fonoaudióloga foi a de querer governar e regular a relação da criança com a língua, enfatizando suas capacidades perceptuais, conforme pode ser visto no episódio 1, que mostra a posição pedagógica assumida pela terapeuta diante do erro na escrita.

O episódio 2, exibe uma conversa com I sobre a possível percepção de sons relacionados ao traço de sonoridade dos fonemas /f/ e /v/.

Episódio 2 - Momento da terapia correspondente à correção do texto escrito pelo participante I. O livro lido tinha sido o $\mathrm{Na} \mathrm{Roça} a^{4}$

Situação: A terapeuta conversava com I sobre as diferenças entre os sons, após a ela ter lido em voz alta o texto produzido por I.

T: Coloca a mão na sua garganta. Faz /f/! (prolongando-o)

\footnotetext{
${ }^{3}$ Trata-se de um livro ilustrado para crianças intitulado Doce água doce, escrito por Regina Rennó e publicado pela Editora Mercuryo Jovem de São Paulo em 2008. O livro é constituído por imagens relacionadas à poluição dos rios e suas possíveis consequências para a população.

${ }^{4}$ Trata-se do livro da autora Mary França, com a ilustração de Eliardo França, publicado em 1992, pela Editora Ática na sua $10^{\mathrm{a}}$ edição.
} 
$\mathrm{I}: / \mathrm{f} /$

$\mathrm{T}: \mathrm{Faz} / \mathrm{v} /$ (prolongando-o)

$\mathrm{I}$ : /v/ (prolongando-o)

T: Qual a diferença de um e de outro?

I: que o /f/ (prolonga um pouco) tem o som mais agudo e o /v/ (prolonga um pouco) tem o som mais grave.

T: Tá. Você fala que o /v/ (prolongando-o) é mais grave, por que é mais forte?

I: É.

$\mathrm{T}$ : O que acontece na garganta quando eu faço o /v/ (prolongando-o)?

I: Treme.

No diálogo acima, a fonoaudióloga buscou ensinar a diferença entre o /f/ e /v/ para I. Com essa atitude pedagógica, a fonoaudióloga deixava transparecer a ideia de "que a presença do sintoma estava relacionada a uma dificuldade relacionada à percepção dos sons da fala". Por isso, apostava que ao "perceber" a diferença de sonoridade, a criança deixaria de errar (Araújo, 2002, p. 101). Segundo Araújo, essa crença de que basta a criança “perceber” para “deixar de errar” é paradoxal, porque

[...] a criança estar inserida numa comunidade em que, a todo tempo, é exposta ao padrão correto de fala. Assim, se a presença do sintoma pudesse ser reduzida a um problema de percepção, por que razão, então, acreditar que a "fala corretora do terapeuta" pudesse provocar mudanças que não aconteceram fora da situação de terapia? (Araújo, 2002, p. 101)

Realmente, parece pouco plausível acreditar que bastaria a criança perceber as diferenças entre os sons e estar exposta a fala correta para solucionar os problemas de fala, leitura e escrita. Porém, quando as crianças são instruídas a escutar (o que é diferente de ouvir) essas diferenças, elas podem produzir efeito de mudanças em suas produções.

O último episódio, apresentado neste artigo, mostra uma cena comum aos atendimentos fonoaudiológicos.

\section{Episódio 3 - Leitura do livro Peixe Pixote}

Situação: A terapeuta corrige a leitura de M, sendo que I também faz uma interferência.

M: Via peixes... peixos

T: Peixinhos.

M: Peixinhos e peixões, via é... pedras de todos os tamanhos e todas as cores e plantas a...

T: Aquáticas

M: Aquáticas, sapos é... a não sei

T: Rãs I: rãs

M: Até sapatos valhos

T: Velhos

M: Velhos e brinquedos de crianças tinha lá.

No episódio 3, M teve todos os seus enunciados corrigidos pela terapeuta, sendo que após cada correção, M repetia a palavra correta dita pela fonoaudióloga no seu enunciado subsequente. Na ocasião do atendimento, a fonoaudióloga sentiu-se satisfeita, por parecer que a criança estava respondendo às solicitações de correção. No entanto, essa interpretação foi modificada após a realização da transcrição da sessão, conforme se verá na próxima seção. É importante também enfatizar que depois de analisar os dados dessa sessão, a investigadora (a terapeuta já situada fora da cena clínica) notou que, em todos os episódios, as correções fizeram com que os diálogos se esgotassem. Ou seja, o efeito produzido pelas inúmeras correções da terapeuta fez calar as crianças.

\footnotetext{
${ }^{5}$ Peixe Pixote é o título do livro publicado pela Editora Ática (5a edição) em 1991, da coleção estrelinha, escrito por Sônia Junqueira e ilustrado por Martin.
} 


\section{Discussão}

Os três episódios apresentados mostraram a preocupação da fonoaudióloga durante os atendimentos em corrigir a fala, escrita e leitura das crianças. Inicialmente, a terapeuta acreditava que estava deixando de lado as práticas da Fonoaudiologia Tradicional, simplesmente porque fazia a discussão dos textos lidos antes de as crianças os escreverem. Porém, a reflexão sobre sua atuação só foi possível num momento seguinte, quando transcreveu as sessões de atendimento e as analisou. Ou seja, quando se colocou fora da cena terapêutica, ao situar-se na posição de investigadora.

Lier-De -Vitto (2004) afirma que há fonoaudiólogos que confiam mais na experiência clínica do que em instrumentos disponíveis na Fonoaudiologia Tradicional, revelando uma prática apoiada na "sensibilidade intuitiva". Cabe ressaltar que, os motivos que sustentavam a terapeuta na posição pedagógica relacionam-se tanto à formação do fonoaudiólogo, quanto à história da Fonoaudiologia. A cuidadosa revisão bibliográfica realizada no decorrer desta pesquisa aponta que as estratégias corretivas adotadas nas sessões de terapia fonoaudiológicas estão presentes na prática do profissional desde a origem da profissão no Brasil. Levando-se em consideração o modo como a terapeuta lidava com a fala, leitura e escrita das crianças durante os atendimentos, via-se claramente sua adesão à concepção de linguagem restringida à comunicação, tão aceita pela Fonoaudiologia Tradicional. Conforme pontua Rubino (1994, p. 74), nesse modelo, a relação entre os interlocutores se dá entre sujeitos unos, que detêm o controle de si mesmos e da linguagem.

No episódio 1, as crianças M e I solicitaram ajuda da terapeuta para escrever as palavras chega e barragem. Em resposta, a terapeuta produziu de forma alongada os fonemas $/ \mathrm{J} / \mathrm{e} / \mathrm{z} /$ para que as crianças chegassem sozinhas à forma correta da palavra. No entanto, o que pode ser observado é que as crianças escolheram letras que poderiam até representar esses fonemas, mas que não eram as formas corretas, de acordo com as normas padrão do português. Quando a terapeuta alongou o fonema $/ \mathrm{S} /$, M disse que a palavra chega escrevia-se $\operatorname{com} x$. Algo semelhante aconteceu, quando a fonoaudióloga alongou o fonema /3/, em que I disse que a palavra barragem deveria ser escrita com $j$. Escapou à terapeuta durante o atendimento, que uma decisão que dizia respeito à ortografia ainda tinha que ser resolvida.

O primeiro enunciado da terapeuta no episódio 1 anuncia o lugar dela no diálogo como quem auxilia as crianças, ao dizer: "vou te ajudar". Só que, em seguida, ao alongar a produção do fonema em sua fala, denuncia sua posição de quem aposta que as relações entre fala e escrita são transparentes para as crianças e até unívocas. Além de se posicionar como aquela que ensina a língua às crianças, tratou-as como sendo capazes de terem condições de manipular, refletir e pensar sobre a língua. Como afirma Leite (2006), a escuta da terapeuta para o sintoma, ao que parece, estabeleceu-se por meio de uma relação transparente entre a percepção auditiva e o erro, como se bastasse à criança reconhecer e perceber o erro para acertar. Entretanto, o episódio 1 mostra que a relação das crianças com a língua pode apresentar certa dose de imprevisibilidade. Isso pode revelar uma forma original (singular) de organização das possíveis relações entre fala e escrita pela criança. Cabe dizer que nem M e nem I apresentavam dificuldades com a sonoridade de fonemas em suas falas e, ocasionalmente, elas ocorriam na escrita.

No episódio 2, no diálogo, a terapeuta se propôs a ensinar a diferença existente na produção dos fonemas /f/ e /v/ em relação à sonoridade. Para isso, fez uso da percepção tátil ao colocar sua mão na garganta, ensinado I a fazer o mesmo, para que ele verificasse a presença da vibração da corda vocal (no caso de /v/) ou ausência desta (no caso de /f/). Assim, neste episódio destacou-se não só a posição pedagógica assumida pela terapeuta, mas também sua crença nas capacidades perceptuais da criança.

No episódio 3, a fonoaudióloga corrigiu peixos da fala de M, ao dizer peixinhos, em seguida. Na sequência dialógica imediata, a criança repetiu peixinhos da fala da terapeuta para sua "própria" fala. Mais adiante, no mesmo diálogo, a 
fonoaudióloga corrigiu valhos da fala da criança, ao dizer velhos. E, na sequência dialógica imediata, M retoma velhos da fala da terapeuta para seu "próprio" enunciado.

Durante o atendimento, a fonoaudióloga - ainda sobre influência dos procedimentos da Fonoaudiologia Tradicional acreditou que estava corrigindo a fala de $\mathrm{M}$, ao ter apresentado à criança as formas corretas peixinhos e velhos em sua fala. A expectativa da terapeuta era de ensino-aprendizagem. Ou seja, a de que ela estava ensinando a língua à criança. E esta, por sua vez, ao imitar as formas corretas ditas pela terapeuta estaria aprendendo a língua, na visão da Fonoaudiologia Tradicional. Entretanto, inúmeros estudos da área de Aquisição da Linguagem (De Lemos 1992, 2002 e Maldonade 1995, 2003) se dedicaram a mostrar que a crença de que a criança, nestes casos, passaria a acertar é muito simplista, porque não basta que a criança produza uma forma "correta" (por imitação), para que esta seja de vez incorporada ao repertório da criança e ela deixe de errar para sempre. Ao contrário, no processo de aquisição da linguagem observa-se uma sequência de "acerto", "erro" e "acerto"; o que foi amplamente reconhecido na literatura como a Curva em U.

Ao analisar o episódio 3, depois de tê-lo transcrito, ou seja, quando a terapeuta se posicionava fora da cena terapêutica, algo novo pode ser salientado: a dependência dialógica mostrada pelos enunciados das crianças. Em outras palavras, foi possível entender que a imitação da fala correta da terapeuta por $\mathrm{M}$, dizia respeito à sua posição subjetiva no processo de aquisição da linguagem, como ainda presa à fala do outro. Tal posição é definida pela teorização interacionista como sendo a primeira posição da criança no processo de aquisição da língua(gem), de acordo com De Lemos (2002) e Maldonade (2015). Em relação aos erros na fala das crianças, esses aparecem em maior proporção na segunda posição do processo de aquisição da linguagem proposto por De Lemos (2002), quando a relação da criança com a língua se torna dominante.

Isso quer dizer que não é o simples ato de repetir a fala do terapeuta (ou seus fragmentos), que garantiria o aparecimento da forma correta na fala da criança. Além disso, observa-se que na fala da criança a partir daí, começam a comparecer acréscimos, restos de outros textos ou até mesmo mudanças de entonação. Isso mostra que a repetição vai para além da incorporação (imitação). Conforme aponta Aspilicueta (2014, p. 115), o que é repetido do texto [da fala] do outro vem com diferenças, pois pode passar pela interpretação do sujeito.

Sendo assim, a repetição da fala correta da terapeuta pela criança pode ser uma mola propulsora para mudança de posição dela no processo de aquisição de linguagem. Porém, o que não se pode garantir é que a repetição da fala correta da terapeuta pela criança possa ser vista como um aprendizado da criança e nem que esta permaneça estável para sempre no repertório da criança. Conclui-se então, que não se trata apenas de olhar para o erro ou acerto na fala da criança, mas de entender que há ainda a posição subjetiva dela no diálogo a ser considerada, marcando sua relação com a fala do outro, com a língua e com sua própria fala.

De modo particular, Spina-Carvalho (2003) afirma que a correção realizada pela terapeuta pode ainda ser considerada uma estratégia interpretativa usada na Clínica de Linguagem. A ideia de que a criança é capturada pelo funcionamento linguístico vem apoiar esta decisão. Neste caso, a aposta da terapeuta não teria relação com "ensinar" ou "aprender" a língua e sim em investir na movimentação dos significantes, que poderiam impulsionar a criança a se deslocar no processo de aquisição da linguagem. De qualquer forma, conforme recomenda a autora, seria preciso que o fonoaudiólogo se mantivesse sempre atento aos efeitos da linguagem.

Ter "escuta para o singular", considerando a "imprevisibilidade da fala do sujeito que está em tratamento" é ponto estruturante para o terapeuta, pois é a partir dos "efeitos que a fala (ou escrita) sintomática" produzem na "escuta" do terapeuta, que se poderia pensar nas intervenções clínicas (Bender \& Surreaux, 2011, p.144).

Ao finalizar esta seção, é preciso deixar registrado que ao analisar os dados, alguns pontos chamaram à atenção da fonoaudióloga - situada fora da cena terapêutica, como por exemplo, o fato de que ela própria falava mais do que as crianças, 
chegando até a ocupar os turnos delas no diálogo. Em outros momentos, a terapeuta parecia querer controlar os sentidos dos enunciados das crianças, chegando mesmo a barrar a relação delas com a língua(gem), ao se fixar no seu script terapêutico (ou planejamento) ou no sentido veiculado pelo texto, que era lido em terapia (v. Ramos, 2018). Além disso, cabe ressaltar que as considerações realizadas neste trabalho, limitam-se aos resultados alcançados pela pesquisa desenvolvida. Para que suas conclusões possam ser generalizadas ou mesmo confirmadas para um número maior de dados, pesquisas futuras precisam ser realizadas.

\section{Considerações Finais}

O artigo buscou refletir sobre a posição da terapeuta ao corrigir a fala/leitura e escrita de duas crianças em atendimento fonoaudiológico. Verificou-se a tendência de corrigir, ensinar a falar, ler e escrever "corretamente", quando a fonoaudióloga estava na cena terapêutica, ocasião em que mostrou sua adesão à Fonoaudiologia Tradicional. Porém, ao transcrever as sessões de terapia, ou seja, ao colocar-se fora da cena clínica, a terapeuta conseguiu refletir sobre a posição pedagógica, que tinha assumido durante os atendimentos realizados. Logo, este se configura como um passo fundamental e necessário para a fonoaudióloga assumir sua posição frente aos atendimentos que realiza.

Isso foi possibilitado pela metodologia adotada no desenvolvimento da pesquisa, que exige que todas as sessões de atendimento sejam transcritas e depois analisadas. Essa exigência tem sido adotada por fonoaudiólogos que trabalham na perspectiva da Clínica de Linguagem, que é também a defendida na conclusão deste trabalho. Sendo assim, a terapeuta pode se escutar várias vezes, produzindo como efeito a reflexão sobre sua própria posição de terapeuta. Arantes (2001, p. 147) afirma que "a transcrição representa uma possibilidade do fonoaudiólogo responder como o sintoma se articula na cadeia significante". Permite ainda ao fonoaudiólogo "se ver e modificar o seu fazer". Dessa forma, a fonoaudióloga pôde refletir e rever sua prática: com uma escuta guiada pela teoria interacionista e olhar atento para os efeitos que a fala da terapeuta provoca na fala, leitura e escrita das crianças, para assim mobilizar mudanças mais significativas na relação da criança com a língua(gem). Para isso, os conceitos de língua(gem) e sujeito tomados criticamente foram fundamentais para entender que não basta apenas se atentar para o erro ou acerto na fala ou escrita da criança. Ao contrário, é preciso olhar para o diálogo e entender como as manifestações linguísticas dos sujeitos se relacionam. Com isso, foi possível a terapeuta dar outra direção e sentido para sua prática fonoaudiológica, ao trilhar um novo caminho junto à Clínica de Linguagem.

\section{Referências}

Arantes, L. (2001). Diagnóstico e clínica de linguagem. [Tese de Doutorado em Linguística Aplicada e Estudos da Linguagem, Pontifícia Universidade Católica de São Paulo].

Arantes, L. (2019). Diagnóstico na clínica de linguagem: escuta e interpretação. Linguística, 35(2), 39-48. https://doi.org/10.5935/2079-312X.20190015

Araújo, S. M. M. (2002). O fonoaudiólogo frente à fala sintomática de crianças: uma posição terapêutica? [Tese de Doutorado em Semiótica e Linguística Geral - Departamento de Linguística da Faculdade de Filosofia, Letras e Ciências Humana, Universidade de São Paulo]

Aspilicueta, P. (2014). Movimento da subjetivação da criança na escrita de texto: entre o texto do outro e o texto próprio. [Tese de Doutorado em Letras Setor de Ciências Humanas, Universidade Federal do Paraná].

Bender, S, \& Surreaux, L. M. (2011). Os efeitos da fala da criança: a escuta do sintoma na clínica de linguagem. Cad. il. (42), 129-145. https://doi.org/10.22456/2236-6385.26017.

Berberian, A. P. (2007). Fonoaudiologia e Educação, um encontro histórico. Plexus Editora.

Capellini, S. A. (2004). Distúrbios de Aprendizagem versus Dislexia. In: L. P. Ferreira, D. M. Befi-Lopes, \& S. C. O. Limongi, (Org). Tratado de Fonoaudiologia. (pp. 862-876). Roca

De Lemos, C. G. (1982). Sobre a aquisição da linguagem e seu dilema (pecado) original. Boletim da Abralin.. 3, 97-126. https://www.abralin. org/site/wpcontent/uploads/2018/12/boletim3a.pdf.

De Lemos, C. G. (1992). Los procesos metafóricos y metonímicos como mecanismos de cambio. Substratum. 1(1), $121-135$. 
De Lemos, C. G. (1995.) Língua e discurso na teorização sobre Aquisição de Linguagem. Letras de Hoje. 30(4), 9-28.

De Lemos, C. G. (2000). Questioning the notion of development: the case of language acquisition. Culture \& Psychology. 6(2), $197-207$.

De Lemos, C. G. (2002). Das vicissitudes da fala da criança e de sua investigação. Cad. de Est. Ling. 42, 41-69. https://periodicos.sbu.unicamp.br/ojs/ index.php/cel/article/view/8637140.

De Lemos, C. G. (2006). Uma crítica (radical) à noção de desenvolvimento na Aquisição da Linguagem. In: M. F. Lier-De-Vitto, \& L. Arantes. Aquisição, patologias e clínica da linguagem. (EDUC, pp. 21-30)

Didier, M. G. S. L. (2001). Fonoaudiologia e sua história em Pernambuco. [Dissertação de Mestrado em fonoaudiologia, Pontifícia Universidade Católica de São Paulo]

Ferreira, H. M. (2011). A relação entre criança/língua/escrita: uma leitura numa perspectiva interacionista. Rev. Alpha. (12), 145-164. https://revistas.unipam.edu.br/index.php/revistaalpha/issue/view/123/Revista\%20Alpha\%20N\%2012\%202011

Fongaro, A. E. M. (2009). Manifestações sintomáticas na escrita e a clínica de linguagem. [Dissertação de Mestrado em Linguística Aplicada e Estudos da Linguagem, Pontifícia Universidade Católica de São Paulo].

Leite, L. (2006). O sintoma na escrita e sua ilusória transparência. In: M. F. Lier-De-Vitto, \& L. Arantes. Aquisição, patologias e clínica da linguagem. (EDUC, pp. 270-275).

Lier-De-Vitto, M. F. (2004). Sobre a posição do investigador e a do clínico frente a falas sintomáticas. Letras de Hoje. 39 (3), 47-59. https://revistaseletronicas.pucrs.br/ojs/index.php/fale/article/view/13902

Lier-De-Vitto, M. F. (2005). Falas sintomáticas: fora de tempo, fora de lugar. Cadernos de Estudos Linguísticos. 47 (1-2), 143-150. https://periodicos.sbu.unicamp.br/ojs/index.php/cel/article/view/8637278/5000.

Lier-De-Vitto, M. F. (2006). Patologia da linguagem: sobre as "vicissitudes das falas sintomáticas". In: M. F. Lier-De-Vitto, \& L. Arantes. Aquisição, patologias e clínica da linguagem. (EDUC, pp. 182-200)

Lier-De-Vitto, M. F, \& Andrade, L. (2008). Considerações sobre a interpretação de escritas sintomáticas de crianças. Estilos clin. 13 (24), 54-71. http://pepsic.bvsalud.org/scielo.php?script=sci_arttext\&pid=S1415-71282008000100005\&lng=pt\&tlng=pt.

Lier-De-Vitto, M. F, \& Emendabili, M. (2015). Uma posição sobre escuta na clínica de linguagem. Linguística. 31 (2), 73-82, <http://www.scielo.edu.uy/scielo.php?script=sci_arttext\&pid=S2079-312X2015000200006\&lng=es\&nrm=iso.

Maldonade, I. R.(1995). Erros na aquisição de verbos com alternância vocálica: uma análise sócio-interacionista. [Dissertação de Mestrado em Linguística, Instituto de Estudos da Linguagem, Universidade Estadual de Campinas, Campinas]

Maldonade, I. R.(2003). Erros na aquisição da flexão verbal: uma análise interacionista. [Tese de Doutorado em Linguística, Instituto de Estudos da Linguagem, Universidade Estadual de Campinas]

Maldonade, I. R. (2010). Erros na aquisição da flexão verbal: reflexividade e constituição do paradigma verbal. Estudos Linguísticos. 39 (2), $462-476$. http://www.gel.hospedagemdesites.ws/estudoslinguisticos/volumes/39/v2/EL_V39N2_03.pdf.

Maldonade, I. R. (2011). Algumas considerações sobre o erro e a autocorreção no processo de aquisição da linguagem. Estudos Linguísticos. v. 40 (2), 539552. https://revistas.gel.org.br/estudos-linguisticos/article/view/1316/862

Maldonade, I. R. (2015). Sobre a analogia e os erros no processo de aquisição da linguagem. Estudos Linguísticos. 44 (2), 530-545. https://revistas.gel.org.br/estudos-linguisticos/article/view/992/574

Maldonade, I. R. (2016). Erros na fala da criança e instâncias subjetivas na sua relação com a língua. Estudos Linguísticos, 45 (2), 367-410. https://revistas.gel.org.br/estudos-linguisticos/article/view/785/1032

Maldonade, I. R. (2018). A (in)flexibilidade pragmática na fala da criança e os erros no processo de aquisição da linguagem. Estudos Linguísticos. 47 (2), 306 318. https://revistas.gel.org.br/estudos-linguisticos/article/view/2033/1368

Meira, I. (1996). História da Fonoaudiologia no Brasil. Dist. da Com. 8 (1), 87-92. https://revistas.pucsp.br/index.php/dic/article/ view/34788.

Munhoz, C. M. F, Massi, G, Berberian, A. P., Giroto, C. R. M., \& Guarinello, A. C. (2007). Análise da produção científica nacional fonoaudiológica acerca da linguagem escrita. Pró-Fono R. Atual. Cient. 19 (3), 249-258. https://doi.org/10.1590/S0104-56872007000300003

Ramos, A. P. M. (2018). Reflexão sobre as posições de terapeuta frente às dificuldades de leitura e escrita na clínica fonoaudiológica. [Dissertação de Mestrado em Saúde, Interdisciplinaridade e Reabilitação - Faculdade de Ciências Médicas, Universidade Estadual de Campinas].

Rubino, R. (1994). Entre ver e ler: o olhar do fonoaudiólogo em questão. IN: M.F., Lier-De -Vitto. (Org). Fonoaudiologia no sentido da linguagem. (Cortez, pp. 69-84)

Saleh, P. B. O. (2008). Aquisição de linguagem e ensino de língua materna: um lugar para a subjetividade. Uniletras. 30(1), 157-172. https://doi.org/10.5212/uniletras.v30i1.192

Santos, B. A. (2017). Atuação fonoaudiológica nos atrasos do desenvolvimento de linguagem: algumas questões e perspectiva. [Dissertação de Mestrado em Saúde, Interdisciplinaridade e Reabilitação - Faculdade de Ciências Médicas, Universidade Estadual de Campinas]. 
Research, Society and Development, v. 10, n. 10, e94101018562, 2021

(CC BY 4.0) | ISSN 2525-3409 | DOI: http://dx.doi.org/10.33448/rsd-v10i10.18562

Schavarem, L.N, Aspilicueta, P, Galli, J. M, \& Cordeiro, M. D. S. G. (2020). A inscrição da escrita da criança: relação do sujeito com rasuras em textos copiados. Distur. Comum. 32(2), 181-195. https://doi.org/10.23925/2176-2724.2020v32i2p181-195

Schirmer, C. R, Fontoura, D. R, \& Nunes, M. L. (2004). Distúrbios da aquisição da linguagem e da aprendizagem. Jornal de Pediatria. 80(2) Supl., 95-103.

Spina-carvalho, D. C. (2003). Clínica de linguagem: algumas considerações sobre interpretação. [Dissertação de Mestrado em Linguística Aplicada e Estudos da Linguagem - Pontifícia Universidade Católica de São Paulo].

Teixeira, A. C. B. (2005). Leitura e Escrita em Fonoaudiologia: A transição de Paradigmas. [Dissertação de Mestrado em Educação - Faculdade de Filosofia e Ciências, Universidade Estadual Paulista Júlio de Mesquita Filho]

Zorzi, J. L. (2004). Desvios na ortografia. In: L. P. Ferreira, D. M. Befi-Lopes, \& S. C. O. Limongi, (Org). Tratado de Fonoaudiologia. (pp. 877-891). Roca 